\title{
Secondary Education Teachers and School Administrators' Views on Positive Organizational Climate
}

\author{
Yücehan Yücesoy $^{1 *}$, Burak Demir ${ }^{2}$, Başak Bağlama $^{3}$, Mert Baştaş ${ }^{1}$, Behçet Öznacar $^{1}$ \\ ${ }^{1}$ Department of Classroom Teaching, Atatürk Faculty of Education, Near East University, North Cyprus, \\ Mersin 10 Turkey, yucehan.yucesoy@neu.edu.tr \\ ${ }^{2}$ Department of Curriculum instruction, Atatürk Faculty of Education, Near East University, North Cyprus, \\ Mersin 10 Turkey, burak.demir@neu.edu.tr \\ ${ }^{3}$ Department of Special Education, Atatürk Faculty of Education, Near East University, North Cyprus, Mersin \\ 10 Turkey, basak.baglama@neu.edu.tr \\ ${ }^{1}$ Department of Classroom Teaching, Atatürk Faculty of Education, Near East University, North Cyprus, \\ Mersin 10 Turkey, mert.bastas@neu.edu.tr \\ ${ }^{1}$ Department of Classroom Teaching, Atatürk Faculty of Education, Near East University, North Cyprus, \\ Mersin 10 Turkey, behcet.oznacar@neu.edu.tr
}

Correspondence: yucehan.yucesoy@neu.edu.tr

\begin{abstract}
This study aims to determine the views of secondary education teachers and school administrators on positive organizational climate. Case study which is one of the qualitative research methods was used in the study. A total number of 15 participants (12 secondary education teachers and 3 school administrators) constituted the study group of the research. A semi-structured interview form developed by the researchers was used as the data collection tool and the obtained data were analyzed with content analysis method. Results are presented with themes and frequencies in the tables. Results are discussed with relevant literature and recommendations for further research and practices are provided. It is expected that this study would shed light to further research and practices in terms of creating a positive organizational climate in secondary education institutions.
\end{abstract}

Keywords: Organizational climate, secondary education teachers, school administrators, views.

\section{Introduction}

Educational organizations play a privileged and important role in the change and development of societies. Educational organizations affect the environment in which they are located and perform the function of raising individuals who will realize and implement the change process. In this respect, education systems and schools have been the focus of interest of societies for centuries. In our age, the importance of education is no longer discussed by anyone, studies are carried out on how to provide education to individuals and how the society can benefit from education in a better manner. Although the concept of climate is a subject studied in many different disciplines, it is expressed as school climate in educational organizations (Demirez \& Tosunoglu, 2017; Busch \& Fernandez, 2019).

Although researchers suggest that school climate will make a difference on the learning environment and student achievement of the school, there is no agreed definition on the concept of climate. Hoy and Miskel (2010) defined the school climate as qualities related to in-school environment that distinguish one school from another and affect the behavior of each member of the school. However, it is seen that most of the definitions of school climate 
are made within the framework of human relations and interaction at school. School climate is an organizational feature that is influenced by everyone including teachers, students, school administrators and parents at school (Calik \& Kurt, 2010).

Climate is a perception and can be seen as a descriptive factor. Descriptions are in the form of expressing emotions by individuals and may differ. School climate can be considered as the personality of the school in a way. The organizational climate of the school is the whole of the internal features that distinguish it from other schools and it is influenced by formal and informal groups in the school. The impact of the school on the student cannot be denied. Therefore, the organizational climate at school directly affects the student and directs his behavior. One of the main functions expected from schools is to achieve effective learning. For this, firstly, a positive learning and school climate must be created in school (Sisman \& Turan, 2004).

Academic development and learning are given importance in a positive school climate; there are positive relationships between students and teachers; all members of the school community respect each other; a fair and consistent discipline policy is followed; family support and participation are considered as important. Therefore, it can be inferred that students' commitment to school is associated with school climate and school satisfaction. Organizational climate is important in improving communication (Kilic, Ustun \& Onen, 2011). Schools must provide a healthy organizational environment and allow people within them to learn at the highest level of personal, social and academic aspects. Schools are responsible for providing a safe environment for students to develop behavioral, emotional and academic. Efforts to create a safe school environment are aimed at reducing inappropriate behavior in school and classroom.

A healthy climate in a school is seen as one of the conditions for increasing school effectiveness and efficiency (Borkar, 2016). Primary education is of great importance both individually and socially as it constitutes the basic education level. It can be said that the success of the successful schools has an important role in creating a positive school climate in their schools. It can be said that there are efforts to create a positive school climate at the core of quality studies in education both in secondary education institutions and other educational institutions (Voight \& Nation, 2016). Considering the importance of a positive organizational climate in the school environment, this study aims to determine views of secondary education teachers and school administrators on positive organizational climate. In accordance with this aim, answers to the following questions were sought in this study:

1. What are the views of teachers and administrators on the factors effective for developing positive school climate?

2. What are the views of teachers and administrators on organizational efficiency of school stakeholders and student motivation?

3. What are the views of teachers and administrators on increasing motivation to ensure a positive school climate?

4. What are the views of teachers and administrators on strategies for increasing the motivation of the staff in the organization (school)?

5. What are the views of teachers and administrators on conditions to ensure efficiency in the organization?

6. What are the views of teachers and administrators on leadership behaviors to ensure a positive organizational climate? 
7. What are the views of teachers and administrators on how organizational climate affect the quality of education practices?

8. What are the views of teachers and administrators on the role of technology in developing a positive organizational climate?

\section{Method}

\subsection{Research Model}

Case study which is one of the qualitative research methods was used in the study. In case studies, one / several events or situations are analyzed in depth and the factors affecting or affected by the situation / event are examined (Cohen, Manion \& Morrison, 2005; Yildirim \& Simsek, 2011). In this study, case study method was considered as the appropriate method for the aim of this research, since it is aimed to determine the views of secondary education teachers and administrators towards positive school climate.

\subsection{Study Group}

Study group of consisted of 15 individuals determined by random sampling method from secondary education teachers and school administrators working in Nicosia district of Northern Cyprus. Of the 15 participants who agreed to participate in the study, 12 are teachers and 3 are school administrators. 7 of the participants are women and 5 of them are men. When the age ranges of the participants by age are examined, it is seen that there are 2 individuals between the ages of 20-29, 9 individuals between the ages of 30-39, 3 individuals between the ages of 40-49 and 1 individual between the ages of 50-59.

\subsection{Data Collection Tool}

As a result of the literature review made for the preparation of the data collection tool, subtitles were developed for the semi-structured interview form developed by the researchers and the appearance and content validity of the form was provided by taking the opinions of 5 different experts. In terms of the meaning and understandability of the prepared materials, 3 experts from the area of Educational Sciences and 2 Turkish Language Literature teachers evaluated the questions and the form was finalized by making the necessary corrections.

Semi-structured interview form was prepared in accordance with the objectives of the research and the explanations were made to teachers and school administrators who participated in the interview. While preparing the questions in the interview form, it was paid attention that the questions were easily understandable by the study group. The final version of the form included 8 questions aiming to obtain the views of secondary education teachers and administrators towards positive school climate.

\subsection{Data Analysis}

The necessary explanations were made about the purpose of the research and contribution of the research to literature and education policy and practices conducted before the questions were asked to the interviewed participants. The research data were collected with the participation of administrators and teachers working in secondary school in the Nicosia district of Northern Cyprus. The data obtained within the scope of the research were evaluated with a holistic understanding. The interviews took place between 15-20 minutes with each school administrators and teachers. In order for the answers given to be more 
effective, focused questions that emphasize the experiences of teachers and administrators were preferred, rather than abstract questions.

All of the questions asked in the interview were made up of open-ended questions that encouraged explanation. Content analysis method was used in the analysis of the data obtained for the research. According to Yildirim and Simsek (2011), content analysis aims to interpret the data similar to each other in a way that the reader can understand. The data obtained at the end of the study were gathered around a certain concept and themes by using the content analysis method. The analysis of the data was carried out in four stages: coding the data, finding themes, editing the codes and themes, and defining and interpreting the findings. In addition to the themes, sample statements of teachers and administrators are presented with coding teachers as $\mathrm{T}$ and administrators as A.

\section{Results}

\subsection{Views of teachers and administrators on the factors effective for developing positive school climate}

Table 1. Views on the factors effective for developing positive school climate

\begin{tabular}{ll}
\hline Themes & $\mathrm{f}$ \\
\hline Unity and togetherness & 6 \\
Good communication & 4 \\
Working conditions & 3 \\
Atmosphere and environment of the workplace & 2 \\
Planning the work to be done & 2 \\
Rewarding & 1 \\
\hline
\end{tabular}

Table 1 shows the views of teachers and administrators on the factors effective for developing positive school climate. As it can be seen, teachers and administrators provided 6 different views. Unity and togetherness and good communication are the most frequent theme obtained. Sample statements are given below:

"In order to create a positive organizational climate, planning the work to be done is needed and this would help teachers and administrators. They would get more benefits from this. Also, it is believed that the unity and doing the work together help to the establishment of positive organizational climate." (T3)

"Rewarding and organizing the atmosphere of the work place help to the betterment of the institutions and establishment of an effective organizational climate." (A1) 


\subsection{Views of teachers and administrators on organizational efficiency of school stakeholders and student motivation}

Table 2. Views on organizational efficiency of school stakeholders and student motivation

\begin{tabular}{lc}
\hline Themes & f \\
\hline Organizational components & 7 \\
Compatible operation & 3 \\
Individuals being productive together & 3 \\
Ethics, beliefs and attitudes & 2 \\
Coming together for a common purpose & 2 \\
\hline
\end{tabular}

Secondary education and school administrators were asked about their views on organizational efficiency and student motivation and 5 different themes were obtained. A sample expression is provided below:

"Steps should be taken to strengthen the inter-individual co-operation in order to sustain the efficiency of the organizations continuously. In order to develop the efficiency of the organizations, the harmonious functioning of the components within the organization should be ensured." (T5)

\subsection{Views of teachers and administrators on increasing motivation to ensure a positive school climate}

Table 3. Views on increasing motivation to ensure a positive school climate

\begin{tabular}{lc}
\hline Themes & $\mathrm{f}$ \\
\hline Understanding students interests & 6 \\
Directing students towards success & 5 \\
Attracting students attention by making the lesson fun and enjoyable & 2 \\
Setting good communication skills in class & 2 \\
\hline
\end{tabular}

According to table 3, there are 4 different themes constituted by the responses of teachers and administrators on increasing motivation to ensure a positive school climate. Results showed that understanding students interests and directing students towards success are crucial factors for increasing motivation to ensure a positive school climate. It is thought that the administrators believe that the students should be motivated for success and friendly communication from the classroom is important. This is likewise emphasized in the context of the importance of healthy communication. A sample expression is provided below:

"To get students more interested in the lesson, learning about their interests help to increase their motivation. A friendly communication is important in order to be able to communicate with the students in a healthy way and to keep them alive and positive." (T11) 


\subsection{Views of teachers and administrators on strategies for increasing the motivation of the staff in the organization (school)}

Table 4. Strategies for increasing the motivation of the staff in the organization (school)

\begin{tabular}{ll}
\hline Themes & $\mathrm{f}$ \\
\hline Equality and honesty must be kept ahead. & 8 \\
Exhibiting a positive attitude. & 5 \\
Listening and understanding well. & 3 \\
Creating collaboration and team spirit. & 3 \\
Giving value to staff feelings and making them feel important. & 1 \\
\hline
\end{tabular}

Table 4 shows the views of teachers and administrators on the strategies for increasing the motivation of the staff in the organization (school) and results revealed 5 different themes. As it can be seen, equality, honesty and exhibiting a positive attitude are the most important strategies. In table 4, when strategic ideas to increase the motivation of the individuals within the organization are examined, it is seen that teachers draw attention to the importance of trying to listen and understand individuals in the same way with a big difference to other opinions. The participants also pointed out the importance of cooperation and team spirit at the highest rate. However, positive attitude from the same point of view is that they are important motivational topics in their emotions such as giving value to students and making them feel that they are important. Below, a sample expression is provided.

"In order to increase the motivation of individuals and focus on the work they do and to get the maximum efficiency from their work, an equal and honest understanding must be kept ahead. Motivation is an important step for success in the organization of cooperation and team spirit." (A2)

\subsection{Views of teachers and administrators on conditions to ensure efficiency in the organization}

Table 5. Conditions to ensure efficiency in the organization

\begin{tabular}{lc}
\hline Themes & $\mathrm{f}$ \\
\hline Keeping organizational climate and culture in a democratic structure. & 5 \\
Providing inservice training support. & 4 \\
Providing positive learning environment & 4 \\
Understanding everyones' needs and interests & 4 \\
Being equal to all & 3 \\
Making the right planning & 2 \\
\hline
\end{tabular}

Table 5 shows the results on the views of teachers and administrators on conditions to ensure efficiency in the organization. When the table is examined, it is seen that the most popular and most useful attitude among the conditions that treating everyone equally is really important. In addition to this, it is observed that the participants will be expected to ensure efficiency in the organization by providing communication, compliance and in-service support and being equal to all. When we look at individual participant groups, we can see that it is important in this regard that the administrators behave equally to the employees and that 
the organizational policy is important, the culture and climate of the organization should be kept in a democratic structure. A sample statement is presented below:

"It may be an important step to create a social school system in order to achieve an efficiency as a result of the work done in the organization, and it is important to act equally among all. Providing in service and training support and understanding everyone's needs and interests are important aspects that will lead to positive organizational climate." (A1)

\subsection{Views of teachers and administrators on leadership behaviors to ensure a positive organizational climate}

Table 6. Views on leadership behaviors to ensure a positive organizational climate

\begin{tabular}{lc}
\hline Themes & $\mathrm{f}$ \\
\hline Making decisions by taking views of everyone & 7 \\
Being objective & 6 \\
Being equal & 4 \\
Using financial resources effectively & 4 \\
Being respectful & 3 \\
Following current technological innovations & 2 \\
Being motivated to learn & 1
\end{tabular}

In table 6, results on the views on leadership behaviors to ensure a positive organizational climate are provided. According to the table, it is seen that there are 7 different themes. As it can be seen, "making decisions by takine views of everyone" and "being objective" are the most frequent themes. A sample statement is provided below:

"I can think about many factors for leadership, but in my opinion, giving importance to the views of all staff and making decisions by paying attention these views are critical. This makes an environment with positive climate created by an effective leader." (T7)

\subsection{Views of teachers and administrators on leadership behaviors to ensure a positive organizational climate}

Table 7. Views on how organizational climate affect the quality of education practices

\begin{tabular}{ll}
\hline Themes & f \\
\hline Creating financial resources & 7 \\
In-service trainings & 6 \\
Teamwork & 3 \\
Taking responsibility & 3 \\
\hline
\end{tabular}

Table 7 shows the results on the views on leadership behaviors to ensure a positive organizational climate. When the 4 different themes obtained are examined, it is seen that teachers and administrators considered that organizational climate affect the quality of education practices in terms of creating financial resources and in-service trainings. A sample statement is provided below:

"Creating financial resources will positively affect organizational climate and increase the quality of education practices in the school." (T2) 


\subsection{Views of teachers and administrators on leadership behaviors to ensure a positive organizational climate}

Table 8. Views on the role of technology in developing a positive organizational climate

\begin{tabular}{ll}
\hline Themes & f \\
\hline Effective teaching process & 6 \\
Innovative practices & 5 \\
Improving communication skills & 4 \\
Interactive management & 2 \\
\hline
\end{tabular}

Table 8 shows the results on the views on the role of technology in developing a positive organizational climate. According to the views of teachers and administrators, technology plays an important role for effective teaching process, innovative practices, improving communication skills and interactive management. A sample statement is provided below:

"As in all areas, technology brings innovation in the school and this entirely leads to a positive organizational climate." (T8)

\section{Discussion and Conclusion}

It is an indispensable factor for educational institutions that want to exist in today's dynamic and variable competition arena in order to create a positive organizational climate. This study aimed to determine views of secondary education teachers and school administrators towards positive organizational climate. In regard to this, results are discussed with relevant literature.

It is the structure and standards known to everyone in the organization. The fact that the organization operates within a certain system and is based on some rules, compliance and standards will provide objective management as an obstacle to uncertainty and inconsistency.

When the participant's opinions about the importance of organizational climate are examined, most of the participants consider the organizational climate as a factor in their work performance. They see motivation as a factor influencing their work performance. They explained motivation as the most influential factor in their productive work. In some studies in the literature, attention is drawn to the relationship between the organizational climate and the motivations of the staff. It is possible to increase the level of employee engagement and motivation by means of the environment and atmosphere to be established in the organization; the negative organizational climate may lead to decreases in motivating conditions (Gray, Wilcox \& Nordstokke, 2017; Barksdale, Peters \& Corrales, 2019; Rahman \& Ashraf, 2020).

When the participant's opinions about the importance of organizational climate are examined, most of the participants consider the organizational climate as a factor in their work performance. They see motivation as a factor in their working performance. They explained that the most influential factor is motivation for work to be efficient. In some studies in the literature, attention is drawn to the relationship between the organizational climate and the motivations of the employees. It is possible to increase the level of employee engagement and motivation by means of the environment and atmosphere to be established in 
the organization and to avoid the negative organizational climate which may lead to decreases in motivating conditions (Yuner \& Burgaz, 2019).

As a result, it could be inferred that creating positive organizational climate in secondary education is crucial and there are many factors for achieving this as revealed by the teachers and administrators participated in the current study. It is believed that this study will shed light to further research and practices in order to fulfill the requirements for creating a positive organizational climate at schools. Based on the research results in this study, more studies can be carried out in order to increase organizational commitment in educational institutions. Efforts can be made for the recognition and adoption of organizational culture by members of the organization. For example, regular meetings, joint events and special days celebrations can be organized where the departments come together and share ideas. Activities should be organized together with academic and administrative staff. The fact that the units know each other and that the functions of the departments are clear and understandable by the whole organization staff will also facilitate the functioning of the organization. Therefore, it can be said that the climate of the organization is an indispensable value and is regarded as an important factor to be considered thoroughly in educational institutions between all stakeholders. 


\section{References}

Barksdale, C., Peters, M. L., \& Corrales, A. (2019). Middle school students' perceptions of classroom climate and its relationship to achievement. Educational Studies, 1-24.

Borkar, V. N. (2016). Positive school climate and positive education: Impact on students well-being. Indian Journal of Health \& Wellbeing, 7(8), 861-862.

Busch, S., \& Fernandez, J. (2019). Influencing high student achievement through school culture and climate: A quantitative approach to organizational health-based leadership. UK: Routledge.

Calik, T., \& Kurt, T. (2010). Development of the school climate scale (SCS). Egitim ve Bilim, 35(157), 167-180.

Cohen, L., Manion, L., \& Morrison, K. (2005). Research methods in education (5th ed.). London: Routledge Falmer.

Yildirim, A., \& Simsek, H. (2011). Sosyal bilimlerde nitel arastirma yontemleri. Ankara: Seckin Yayıncılik.

Demirez, F., \& Tosunoglu, N. (2017). Orgut ikliminin ise yabancilasma uzerine etkisi: Gazi Universitesi rektorlugunde bir arastirma. Isletme Arastirmalari Dergisi, 9(2), 69-88.

Gray, C., Wilcox, G., \& Nordstokke, D. (2017). Teacher mental health, school climate, inclusive education and student learning: A review. Canadian Psychology/psychologie canadienne, 58(3), 203-210.

Hoy, W. K., \& Miskel, C. G. (2010). Egitim yonetimi (translation ed. S. Turan). Ankara: Nobel Yayin Dagitim.

Kilic, E. D., Ustun, A., \& Onen, O. (2011). Ogrenen orgutlerde etkili liderlik: Burdur ornegi. Educational Policy Analysis and Strategic Research, 6(1), 5-22.

Rahman, A. K., \& Ashraf, P. (2020). A Study on The influence of school organizational climate and attitude of teachers. Our Heritage, 68(1), 3709-3712.

Sisman, M., \& Turan, S. (2004). Bazi orgutsel degiskenler acisindan calisanlarin is doyumu ve sosyal-duygusal yalnizlik duzeyleri. Eskisehir Osmangazi Universitesi Sosyal Bilimler Dergisi, 5(1), 117-128.

Voight, A., \& Nation, M. (2016). Practices for improving secondary school climate: A systematic review of the research literature. American Journal of Community Psychology, 58(1-2), 174-191.

Yuner, B., \& Burgaz, B. (2019). Evaluation of the relationship between school governance and school climate. Education and Science, 44(199), 373-390. 